\title{
Tribology and Maintenance of Machinery - A Review
}

\section{Chandan Chattoraj}

\begin{abstract}
The present paper considers the tribological principles on the maintenance of machinery whose three important areas are - Preventive, Condition Based and Proactive. Although breakdown is kept out of view, the morphology and analysis of failure provide important inputs for maintenance strategies. Condition based maintenance depends on three D's Detection, Diagnosis and Decision. In many machinery systems, the problem of predicting the remaining useful life - the Proactive part of the program, and evaluating the cost benefits are of enormous importance. Here the authors endeavor to highlight how the tribologist can significantly improve the maintenance practice.
\end{abstract}

Keywords: Tribology, Preventive, Condition-based, Pro-active maintenance.

\section{INTRODUCTION}

'TRIBOLOGY' a word of recent origin is a study of Friction, Lubrication and Wear. The British Lubrication Engineering Working Group (1966) put it as "the science and technology of interactive surfaces in relative motion and the particles related there to". Whatever may be the genesis of the word, the question of friction, lubrication, and wear were reasonably understood by our fore fathers, even before the beginning of the history.

Friction is helpful in many types of machinery for their operation; it is astonishing to learn that about one third of the global energy production is wastefully drained out by friction alone. Friction and wear are inseparably connected phenomenon and considering the fact that world economy rests on energy efficiency, tribology has gained a position of supreme importance today.

Possibly no industrial unit can afford to throw away its utilized to their fullest extent of life with maximum reliability and performance. Hence the concept of Maintenance arises. Many people had defined the term maintenance in different respect. But the following flowchart (fig: 1.1) defines the maintenance in a generalized view:

Manuscript received on April 10, 2021.

Revised Manuscript received on April 14, 2021.

Manuscript published on June 10, 2021.

* Correspondence Author

Chandan Chattoraj*, Professor, Mechanical Engineering Department, Dr. B. C. Roy Engineering College, Durgapur, West Bengal, India, PIN: 713206. Email: chandan.chattoraj@bcrec.ac.in

(c) The Authors. Published by Lattice Science Publication (LSP). This is an open access article under the CC BY-NC-ND license (http://creativecommons.org/licenses/by-nc-nd/4.0/) machineries i.e. capital resources, unless they have been

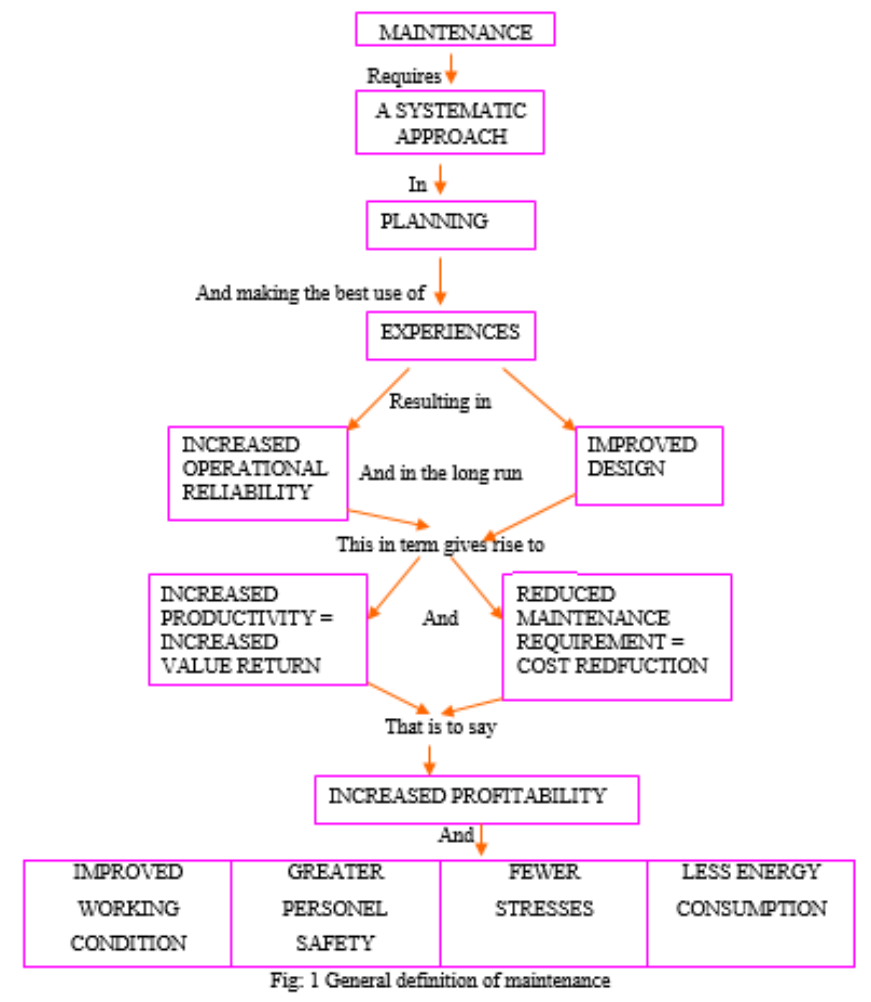

In this presentation the tribological aspects and maintenance practice are co related to ensure that critically operating machinery fulfils their intended function and to continue for pre-expected life time.

\section{TRIBOLOGICAL PRINCIPLES APPLIED TO MAINTENANCE PRACTICE:}

\section{A. Maintenance practice - a review}

Prior to World war II, the maintenance of machine was performed on the break down principle. In this sort of practice the machines were the machines were continuously kept in service until it could not continue its normal function any further, which means "Don't fix it, until it is broken". During this concept the human senses like eyes, ears, smell, touch and even taste was considered during observation during observation. But this would lead to disruption of production plans as the type and the type of break down are of random nature and may even cause loss of life. Meanwhile the concept preventive maintenance was evolved during which the equipment were regularly investigated on the daily weekly, monthly or shutdown basis. During this, the faulty parts were get repaired/replaced, improving the life of the equipment.

\section{Published By:}

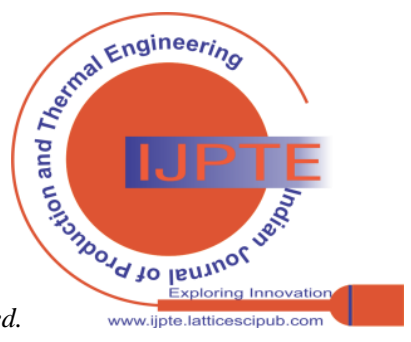


But this concept was further modified as it was not taken care of abnormality and sudden change of the equipment parameters. This background developed a new concept in maintenance practice well known as condition-based maintenance in which abnormality of machineries and change-in equipment parameters were taken care of in addition to preventive maintenance. Some industry had adopted the new concept in demand, proactive i.e. root cause analysis for predicting the remaining future life of any equipment.

All these concepts may be used by any industry all together or individual one. This is totally depending upon the whole spectrum of the industry i.e. the type of business involved, the type of machinery deployed and the workforce availability - skill level and turnover of staff. The significance of adopting these approaches is to find an answer for the question of "fail to fulfill its function", and what may cause that "loss of life"?

\section{B. Tribology - its principle:}

Friction, Wear between mating surfaces, and Lubricationthese are three major areas of tribology. As the technology is developed the modern machines are designed for "providing more power", in a small size. As a result, very small area available in the contact of mating surfaces to transmit the requisite increase in load at high speeds. At higher speeds the instability and the temperature rise are the main two threats for the continued smooth operation. Due to limitation for improving the properties of the material (mating surfaces and lubricant), friction and consequent wear will increase, with a corresponding rise in temperature and removal of surface material leading to either seizure or instability due to unacceptable wear. To overcome this drawback the lubrication theory was developed.

In the later 70's when there was a relative increase in the cost of energy arising from the energy crisis the clear indication was to conserve energy and raw materials by improved design applying tribological principle. But that time very few industries were realized/aware the necessities or possibilities for improvement in their practices by applying tribological principle. Even they are not sure to decide which machinery health monitoring techniques were best suited for their purpose. Now industries have realized the safety as the highest priority, therefore more concentration had been given to the maintenance practice.

\section{Tribology and Maintenance:}

Now-a-days the concept -"Prevention is Better than Cure"is applied along with the outcomes of tribological research, for manufacturing components with improved design. With this application a marked change in the performance of machinery is observed. Throughout the major areas of maintenance activity, tribological principles (table:01) applied are - Preventive, Condition based and Proactive.
Table:01

\begin{tabular}{|c|l|l|}
\hline Maintenance activity & \multicolumn{1}{|c|}{ Tribological input } & \multicolumn{1}{c|}{ Decision } \\
\hline Preventive & $\begin{array}{l}\text { Checks all the probable causes } / \\
\text { parameters prone to failure at } \\
\text { regular interval. }\end{array}$ & $\begin{array}{l}\text { Replace /change the } \\
\text { parameter/ causes to their } \\
\text { pre-designed value. }\end{array}$ \\
\hline Condition based & $\begin{array}{l}\text { More attention to the parameters } \\
\text { having highest priority towards } \\
\text { failure. }\end{array}$ & $\begin{array}{l}\text { Supplant / cause } \\
\text { accordingly. }\end{array}$ \\
\hline Proactive & $\begin{array}{l}\text { Analyze the causes of failure at } \\
\text { the root level. }\end{array}$ & $\begin{array}{l}\text { Prediction of remaining } \\
\text { wear life on the basis of } \\
\text { root causes. }\end{array}$ \\
\hline
\end{tabular}

\section{FAILURE ANALYSIS:}

The term 'Failure' is widely used to indicate the loss of ability to perform specified function. To identify and isolate the causes of failure an analysis is often carried out in three functional areas - design, production and end-use environment. The failure pattern, frequently described as the life cycle from cradle to grave, commences with a high incidence of infant mortality exhibiting high failure rate related to tribological components such as wear debris production rate, intensity of noise, etc. This is followed by a constant or slowly increasing failure rate and finally by a wear out zone, where component replacement becomes essential.

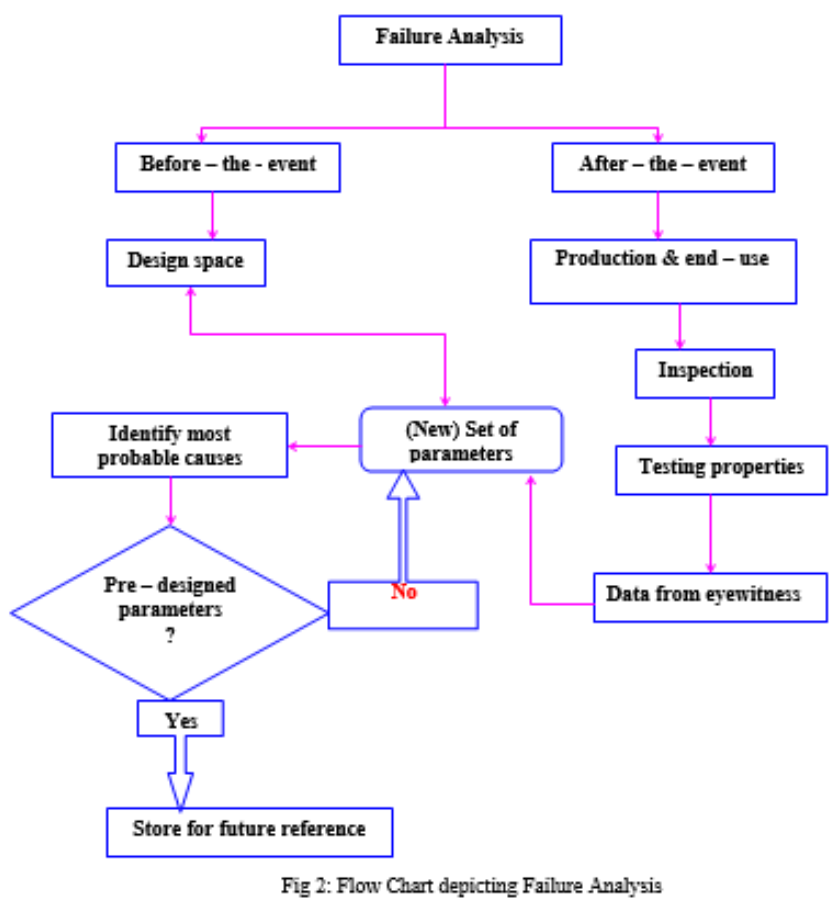

To determine the most probable causes of failure the following steps may be followed:

a) Thorough inspection of the machinery and failed parts.

b) Study carefully the changes in mechanical and chemical properties of the failed parts in the laboratory.

c) Collect the relevant data from eyewitness and compare it with the data related to operating condition.

d) Study all the parameters in the design space.

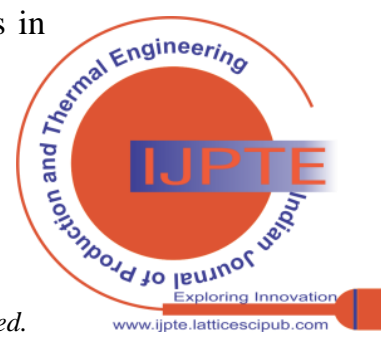


e) Identify the most probable causes and compare it with the pre-designed parameter envelope.

f) If it violates, create a new set of parameters for the design space, otherwise store information for future reference.

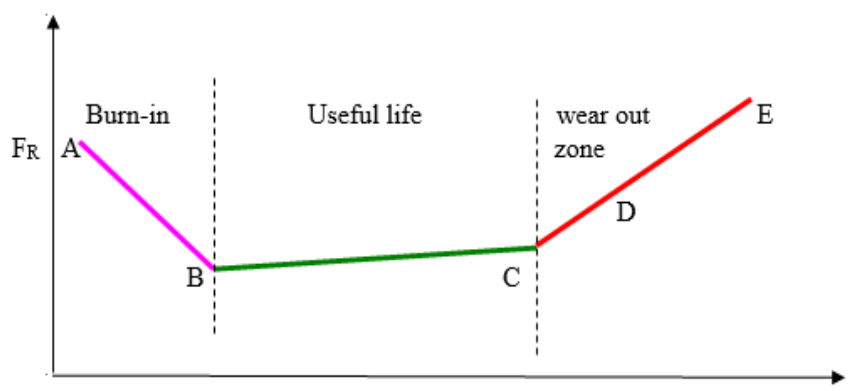

Time(t)

Fig.3: Life cycle of machinery on Log-Log scale

A - New or next repaired
Machine.
B - Useful life begins.
C - First alarm (Indication
towards failure).
D - Second alarm (repair).
E - Machine failure.

\begin{tabular}{|c|c|c|c|}
\hline \multicolumn{4}{|c|}{ Table:02 } \\
\hline & Significant Nature & Probable causes & Measures to be adopted \\
\hline Burn-in & Decreasing failure rate & $\begin{array}{c}\text { Welding flaws, } \\
\text { cracks, defective } \\
\text { parts, poor quality } \\
\text { control, } \\
\text { contamination, poor } \\
\text { workmanship. }\end{array}$ & $\begin{array}{l}\text { - Burn -in testing } \\
\text { - Screening } \\
\text { - Quality control } \\
\text { - Acceptance testing }\end{array}$ \\
\hline Useful life & Constant failure rate & $\begin{array}{l}\text { Environment random } \\
\text { loads, human error, } \\
\text { chance events } \\
\text { ('Acts of God') }\end{array}$ & $\begin{array}{l}\text { - Redundancy } \\
\text { - Excess strength }\end{array}$ \\
\hline $\begin{array}{l}\text { Wear out } \\
\text { zone }\end{array}$ & Increasing failure rate & $\begin{array}{l}\text { Fatigue, corrosion, } \\
\text { aging, friction, cyclic } \\
\text { loading }\end{array}$ & $\begin{array}{l}\text { - De rating } \\
\text { - Preventive } \\
\text { maintenance } \\
\text { - Parts replacement } \\
\text { technology } \\
\end{array}$ \\
\hline
\end{tabular}

The mathematical relation between the failure rate and time is given by,

$$
F_{R}=(\beta / \theta) \times(t / \theta)^{\beta-1} \quad \text { for } \beta>0, \theta>0, t \geq 0
$$

where $\beta$ is a shape parameter, in the burn-in region $\beta<1$, in the useful life $2 \geq \beta \geq 1$ and in the wear-out zone $\beta \geq 2$

$\theta$ is a scale parameter tat influences both the mean and the spread, or dispersion of the distribution.

However, taking natural logarithm on both sides yields,

$$
\begin{aligned}
& \ln \left(F_{R}\right)=(\beta-1) \ln (t)+(\beta-1)[\ln (\beta)-2 \ln (\theta)] \\
& \ln \left(F_{R}\right)=(\beta-1) \ln (t)+C \\
& \text { where } C \text { is a failure parameter which is a function of }
\end{aligned}
$$
$\beta$ and $\theta$, in the burn-in region $\beta<1$, in the useful life 2 $\geq \beta \geq 1$ and

in the wear-out zone $\beta \geq 2$.
Reliability function $\mathrm{R}(\mathrm{t})=\exp \left[-\int\left[(\beta / \theta) \times\left(\mathrm{t}^{\prime} / \theta\right)^{\beta-1} \mathrm{dt}^{\prime}\right]=\right.$ $\exp \left[-(t / \theta)^{\beta}\right]$

Probability density function $\mathrm{f}(\mathrm{t})=-[\mathrm{dR}(\mathrm{t}) / \mathrm{dt}]=\{(\beta / \theta) \mathrm{x}$ $\left.(\mathrm{t} / \theta)^{\beta-1}\right\} \times \exp \left[-(\mathrm{t} / \theta)^{\beta}\right]$

Mean Time To failure $(\mathrm{MTTF})=\underset{0}{\vdots} \mathrm{t} f(\mathrm{t}) \mathrm{dt}=\theta \Gamma\{1+(1 / \beta)\}$

$\left[\right.$ MTTF $=\int_{0}^{\vdots} \mathrm{t} f(\mathrm{t}) \mathrm{dt}=\int_{0}^{\vdots}\left[\left\{(\beta / \theta) \times(\mathrm{t} / \theta)^{\beta-1}\right\} \times \exp \left\{-(\mathrm{t} / \theta)^{\beta}\right\}\right] \mathrm{t} d \mathrm{t}$

Let $\mathrm{y}=(\mathrm{t} / \theta)^{\beta}$, then $\mathrm{dy}\left\{(\beta / \theta) \mathrm{x}(\mathrm{t} / \theta)^{\beta-1}\right\} \mathrm{dt}$,

MTTF $=\int_{0}^{:} \mathrm{t}^{-\mathrm{y}} \mathrm{dy}$, since $\mathrm{t}=\theta \mathrm{y}^{1 / \beta}$, we have

$$
\begin{aligned}
\text { MTTF } & =\theta \int_{0}^{\vdots} \mathrm{y}^{1 / \beta} \mathrm{e}^{-\mathrm{y}} \mathrm{dy} \\
& =\theta \Gamma\{1+(1 / \beta)\}
\end{aligned}
$$$$
\underset{0}{\text { since } \left.\Gamma(x)=\int y^{x-1} e^{-y} d y\right\}} \text { ] }
$$

For example, a compressor experiences the following failure rate function:

$$
\begin{gathered}
\begin{aligned}
\ln \left(\mathrm{F}_{\mathrm{R}}\right) & =-0.1 \cdot \ln (\mathrm{t})+\mathrm{C}, \beta=0.9 \& \theta=1000 \\
& =\mathrm{C}
\end{aligned} \\
, \begin{aligned}
\beta=1 & \& \theta=1000 \text { - } \\
& =\ln (\mathrm{t})+\mathrm{C}, \beta=2 \& \theta=1000
\end{aligned}
\end{gathered}
$$

MTTF $=\mathrm{t}_{1}+\mathrm{t}_{2}+1000 \Gamma\{1+(1 / 2)\}=\mathrm{t}_{1}+\mathrm{t}_{2}+886.23 \mathrm{hrs}$ $\mathrm{t}_{1}+\mathrm{t}_{2}$ can be calculated from log-log plot equation (i), (ii) and (iii) can be simplified by imposing the given conditions.

$$
\begin{aligned}
\ln \left(F_{R}\right) & =-0.1 \ln (t)+1.39 \text {------------------(ia) } \\
& =0 \\
& =\ln (\mathrm{t})-13.12 \quad \text {---------------------(iiia) }
\end{aligned}
$$

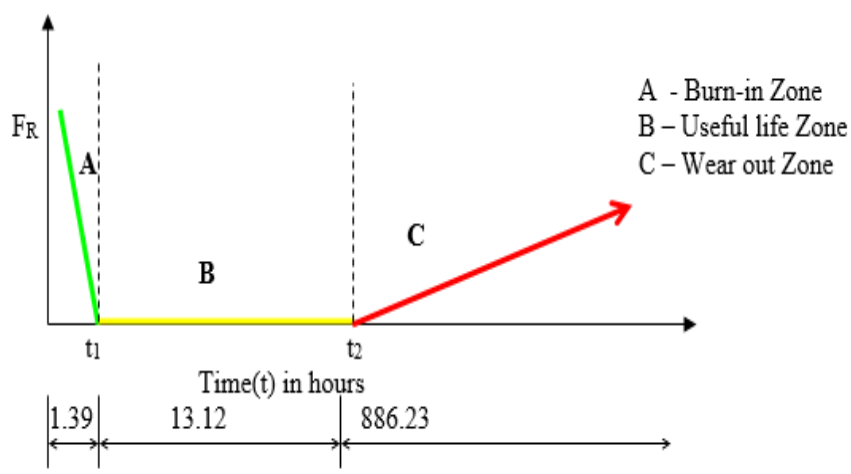

Fig 4: Life cycle of compressor 

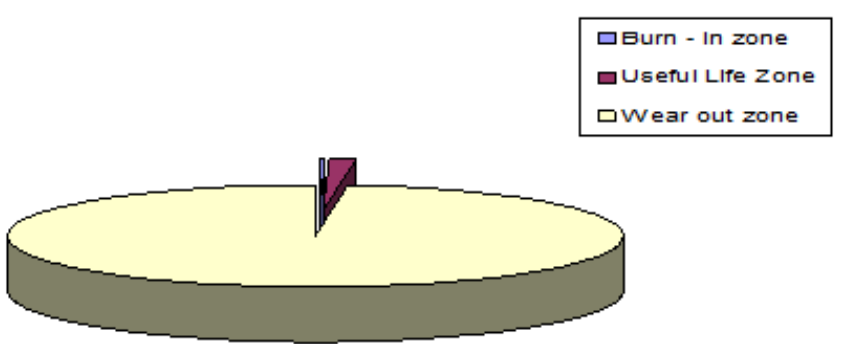

Fig 5: Percentage Life cycle of a compressor

\section{A. Preventive maintenance:}

It can be termed as planned maintenance of the equipment conducted periodically to locate faulty condition and take preventive actions to avoid or minimize chances of delay, thereby, this method ensures long and safe working of the equipment without any mishap. As the preventive maintenance is based on overhauling time, previously experienced and expected life of wearing components, the action may often be taken before it is really necessary and reliability of the equipment is ignored. This technique does not guard against unexpected deterioration between overhaul, as there is no monitoring system is provided. Hence the development of different concept in maintenance system arises.

\section{B. Condition Based Maintenance:}

In condition-based maintenance the monitoring system plays the most important role in detecting the condition of machine. Condition monitoring will provide the regular data for assessing the machine condition as well as to aware when precautions will have to be taken. The merits of condition-based maintenance are:

i) Increasing reliability by reducing the probability of sudden/unexpected failure

ii) Increasing the time interval between consecutive overhauls

iii) Reducing un-necessary replacement of machine parts

The most commonly used monitoring system (table:03) related to tribology is:

\begin{tabular}{|l|l|}
\multicolumn{1}{|c|}{ Technique } & \multicolumn{1}{c|}{ Purpose } \\
\hline Vibration analysis & To check the dynamic instability due to lose fittings \& misalignments \\
\hline Thermography & $\begin{array}{l}\text { Temperature surveillance technique to study mechanical \& chemical } \\
\text { properties }\end{array}$ \\
\hline Wear debris analysis & To find mode of wear, debris size analysis, type of wear \\
\hline Intensity of noise & $\begin{array}{l}\text { To detect the abnormality in machines (by experienced maintenance } \\
\text { personnel) }\end{array}$ \\
\hline Lubricant analysis & To check the quality \& quantity of the lubricant. \\
\hline
\end{tabular}

\section{Proactive Maintenance:}

It is a combination of condition-based maintenance and the data available from the previous failure. The raw data were collected from monitoring system and compiling with the previous failure data, prediction of the remaining life of a machine can be made. This is generally done on the basis of probability of failure before the next major overhaul. Most critical repairs get the highest priority during minor overhaul and less critical repair is deferred to the major overhaul, reducing the overall down time.

\section{WEAR DEBRIS ANALYSIS:}

Wear debris analysis was first developed in U.K by means of Magnetic Debris Plug (MDP) in the lubricating systems. But the most significant development was the ferrography technique. By this technique the morphological characteristic of the debris is identified and compared with the standard observation charts. Debris analysis gives the idea of type of wear that is occurred, by the worn surface and the size of the wear particle. It also ensures about the mode of wear (i.e. due to rubbing, cutting, severe sliding or any other mechanical operations) from the size and surface of the debris.

For establishing a definite relationship between different wear condition and their associated wear debris generally a programmed base database is developed. Regarding this procedure a large number of tests are performed on the same machine under different operating condition on the probability basis, and a comprehensive wear particle data base was acquired. A monitoring technique of debris analysis is shown in figure 06.

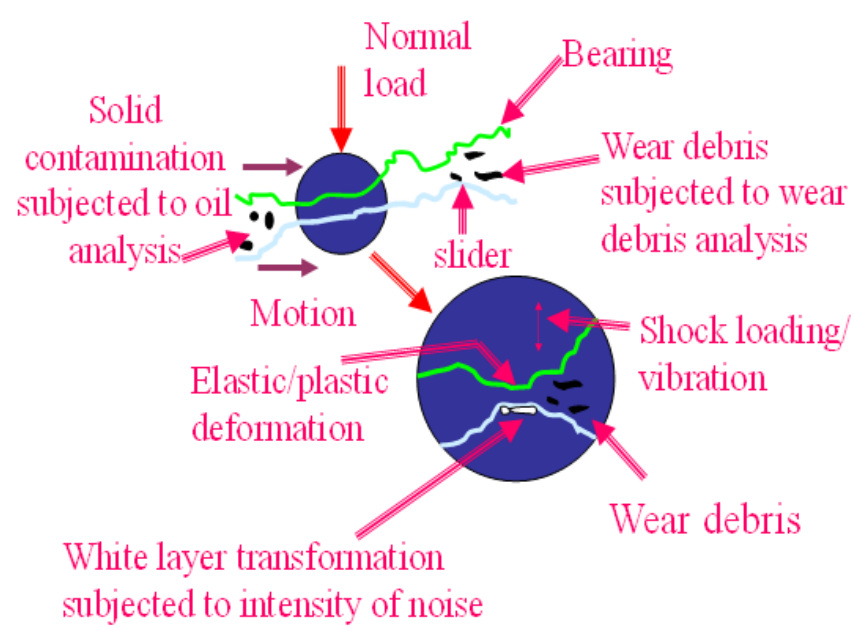

Fig: 6 Analysis of debris

\section{CONCLUSION:}

The effective maintenance of machinery lies primarily in approximately communicating knowledge of its tribological behavior and the practical consequences in relation to failure analysis. Implementation of three D's - Detection, Diagnosis and Decision in the field of maintenance of machinery may hopefully ensure safe, reliable and efficient operations and help any industry to achieve profitable value return amongst competitive.

Finally,

1. Application of tribological principles on maintenance of machinery help to predict the remaining useful life of the failing machinery.

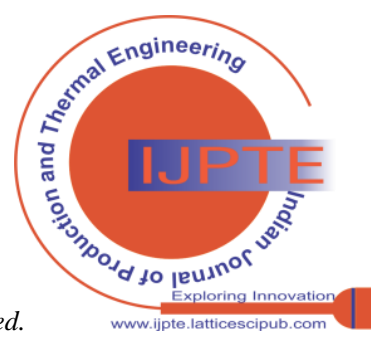


2. By balancing preventive, condition-based and pro-active maintenance practices availability of machinery can be improved.

3. Total expenditure can be minimized by reducing the spare part stock.

\section{ACKNOWLEDGEMENT}

The authors are highly indebted to the authority, Dr. B. C. Roy Engineering College, Durgapur for kind help and support. The authors express sincere thanks to the Mechanical Engineering Department for their help and support.

\section{REFERENCE}

1. Royalance B J, 'Machine failure and its avoidance - what is tribology's contribution to effective maintenance?', Proc. Instn Mech. Engrs Vol. 217 Part J: J. Engineering Tribology.

2. Bachschmid N., Pennacchi P. and Vania A., 'Identification of Multiple Faults in Rotor Systems',Journal of Sound and Vibration, Vol.254, No.2(2002), pp327-366.

3. Platz R. and Markert R., 'Faults Models for Online Identification of Malfunctions I Rotor Systems', Proc. Of Surveillance 4-Acoustical and Vibratory Surveillance Methods and Diagnostic Techniques, Compiegne, France,(2001), pp435-446.

4. Mowbray J., 'Reliability-centred Maintenance', 1991(Butter-worth-Heinemann,Oxford)

5. Hunter R.C., 'Engine failure prediction technique', Aircraft Engng, 1975

6. Seiffert W.W. \& Westcott V.A., 'A Method for te study of Wear particles in lubricating oil', Wear, 1972, 21, pp27-42.

7. Williams J.A., "Engg. Tribology", Oxford University Press, NY, 1994

8. Andras Z Szery to "Fluid Film Lubrication, Theory and Design", Univ Press, 1998.

9. Majumdar B.C., " Introduction to Tribology of Bearings", 1ed,1986, a.h.wheeler, India.

10. Reshetov D.N., "Machine Design”, MIR PUBLISHER, MOSCOW.

\section{AUTHORS PROFILE}

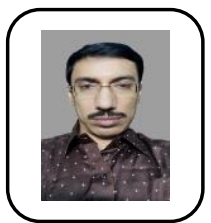

Dr.Chandan Chattoraj, is Professor of Mechanical Engineering Department, Dr. B. C. Roy Engineering College, Durgapur. $\mathrm{He}$ completed his B.E. and M.Tech from NIT Durgapur. He was awarded with University Gold Medal. He also received his Ph.D from NITD. He authored many research papers in International \& National Journals. He authored a book - Theory and Applications of Robotics. His major research interests are Dynamics of Machines, Rotordynamics, Robotics. 